\title{
Triphasic Waves: Clinical Correlates and Morphology
}

\author{
Mecheri B.M. Sundaram and Warren T. Blume
}

ABSTRACT: Twenty-six (41\%) of 63 consecutive patients with triphasic waves had various types of metabolic encephalopathies while 37 patients $(59 \%)$ had non-metabolic encephalopathies, usually senile dementia. Triphasic waves were not found to be specific for any single type of metabolic encephalopathy.

Etiology was more closely linked to conscious level at recording than any morphological or distributional feature of the triphasic waves themselves. Thus, all 31 alert patients had non-metabolic encephalopathies while all 13 comatose patients had metabolic encephalopathies.

The second, positive, component (Wave II) most often had the highest voltage while equally maximal Waves I and II occurred next most commonly. Triphasic waves were most often maximally expressed anteriorly.

Among patients with metabolic encephalopathies, a posterior-anterior delay or lag of the wave 11 peak occurred more commonly than did the better known anterior-posterior lag. Lags occurred with both metabolic and nonmetabolic conditions, but were more common with the former. No difference in quantity or mode of appearance existed between the metabolic and non-metabolic groups when matched for conscious level.

Prognosis for patients with either metabolic or non-metabolic encephalopathies was unfavourable. Only 4 of 24 metabolic and one of 35 non-metabolic patients were well at follow-up over 2 years later.

Forty percent of EEGs with sharp and slow wave complexes (slow spike waves) had sporadically-appearing triphasic waves. The relative amplitudes of the 3 components differed from triphasic waves in other conditions: equally maximal Waves II and III were the most usual form.

RÉSUMÉ: Ondes triphasiques: corrélations cliniques et morphologie Nous avons étudié une série de 63 patients consécutifs présentant des ondes triphasiques: parmi ceux-ci, 26 patients (41\%) étaient atteints de différents types d'encéphalopathies métaboliques, alors que 37 patients $(50 \%)$ avaient des encéphalopathies non-métaboliques, la plus fréquente étant la démence sénile. Les ondes triphasiques ne se sont pas avérées spécifiques d'un type unique d'encéphalopathie métabolique.

L'étiologie était reliée plus étroitement au niveau de conscience du patient au moment de l'enregistrement qu'à toute autre caractéristique de la morphologie ou de la répartition des ondes triphasiques elles-mêmes. Ainsi, les 31 patients dont l'état de conscience n'était pas altéré présentaient des encéphalopathies non-métaboliques alors que les 13 patients comateux étaient atteints d'encéphalopathies métaboliques.

La deuxième composante positive (l'Onde II) avait le plus souvent le voltage de plus élevé alors que des Ondes I et II également maximales étaient les deuxièmes plus fréquentes. L'expression des ondes triphasiques était le plus souvent maximale à la région antérieure.

Parmi les patients porteurs d'encéphalopathies métaboliques, un délai ou un décalage postérieur-antérieur du pic de l'onde II se rencontrait plus souvent qu'un décalage antérieur-postérieur mieux connu. Des décalages étaient présents dans les encéphalopathies métaboliques et non-métaboliques, mais elles étaient plus fréquentes dans cette dernière affection. Il n'existait pas de différence dans leur quantité ou leur aspect entre les groupes porteurs d'encéphalopathie métabolique et non-métabolique quand ils étaient appariés pour le niveau de conscience.

Le pronostic des patients porteurs d'encéphalopathies métaboliques et non-métaboliques était défavorable: seulement 4 des 24 patients avec encéphalopathie métabolique et 1 des 35 patients avec encéphalopathie nonmétabolique étaient bien lors de l'examen port-thérapeutique deux ans plus tard.

Quarante pourcent des EEG présentant des complexes pointe lente-onde lente présentaient aussi des ondes triphasiques d'apparition sporadique. L'amplitude relative des trois composantes différait des ondes triphasiques dans d'autres entités, la forme la plus courante étant des ondes II et III également maximales.

Can. J. Neurol. Sci. 1987; 14:136-140

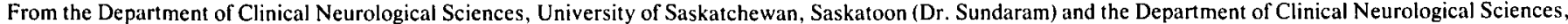
University Hospital. University of Western Ontario, London, Ontario (Dr. Blume)

Received February 20, 1986. Accepted in final form December 4, 1986.

Reprint requests to: Dr. W.T. Blume, EEG Department, University Hospital, 339 Windermere Road, London, Ontario, Canada N6A 5A5 
The common association of triphasic waves (TWs) with hepatic encephalopathy has been known since early descriptions of this EEG phenomenon. ${ }^{1.2 .3}$ In fact, Reiher $(1970)^{4}$ concluded that TWs fulfilling several morphological criteria were pathognomonic for hepatic coma. However, TWs have been found with a wide variety of disorders affecting the brain diffusely. ${ }^{4,5,6}$ Intrigued by this apparent duality of significance, we explored the clinical correlates of TWs by examining their morphology and behaviour, associated EEG features, and patient state at recording.

Triphasic waves and sharp and slow wave complexes (SSWC) share many morphological features. ${ }^{2}$ Therefore, in the second phase of the study we searched for TWs in EEGs containing SSWCs to determine their incidence in this setting and to compare their morphology with that of other TWs.

\section{Method AND MateriaL}

From observations by Bickford and Butt, we defined TWs as bilaterally synchronous bursts or runs whose waveforms have three phases; negative (wave I), positive (wave II) and negative (wave III) (Figure 1). The occasional low amplitude surface positive wave that precedes Wave I was termed wave 0 . As the repetition rate of TWs is about 2-3 Hertz, the duration of each complex would have to fall between 333 and $500 \mathrm{msec}$.

Recordings were made using the International Ten-Twenty system of electrode placement with both bipolar and ipsilateral ear referential montages. The latter best displayed the relative amplitude of TW components. Each EEG lasted at least 30 minutes.

Sixteen thousand six hundred and forty-one EEGs representing 10,476 patients were recorded in our laboratory between 1978 and 1982 . Of these, $78(0.47 \%)$ from 65 patients $(0.6 \%)$ contained TWs. After excluding 8 channel tracings and those showing less than 5 TWs, 66 EEGs on 63 patients remained.

\section{EEG Analysis}

Relative amplitudes of individual waves in each TW were assessed by measurement from the visually determined baseline prior to the complex. A single wave of the triphasic complex was considered "prominent" if its amplitude usually exceeded the second largest wave by more than $50 \%$. If the difference in amplitude between the two largest waves was less than $50 \%$, then two waves were considered equally prominent. Using these criteria, a pilot study found the following patterns of relative amplitudes: Wave II only, Waves I and II, and Waves II and III. Three virtually equally large waves were rarely encountered. The two most frequently occurring patterns were identified in each EEG. In the pilot study, one or two types predominated on each EEG.

Areas of maximum expression were grouped into anterior, posterior, and diffuse. Anterior-posterior time delay (or lag) and posterior-anterior delay, when visibly present, were noted using the peak of wave II (Figure 1). Quantity of TWs was classified as a) abundant: more than 10 bursts per 100 seconds, b) moderate: 6-9 bursts per 100 seconds, and c) minimal: 5 or less bursts per 100 seconds. TWs appeared either as a) single bursts, b) short runs of 2-5 consecutive TWs, or c) long runs of more than 5 consecutive TWs. The quantity and mode of occurrence of TWs were compared according to the etiology of encephalopathy and to level of consciousness.

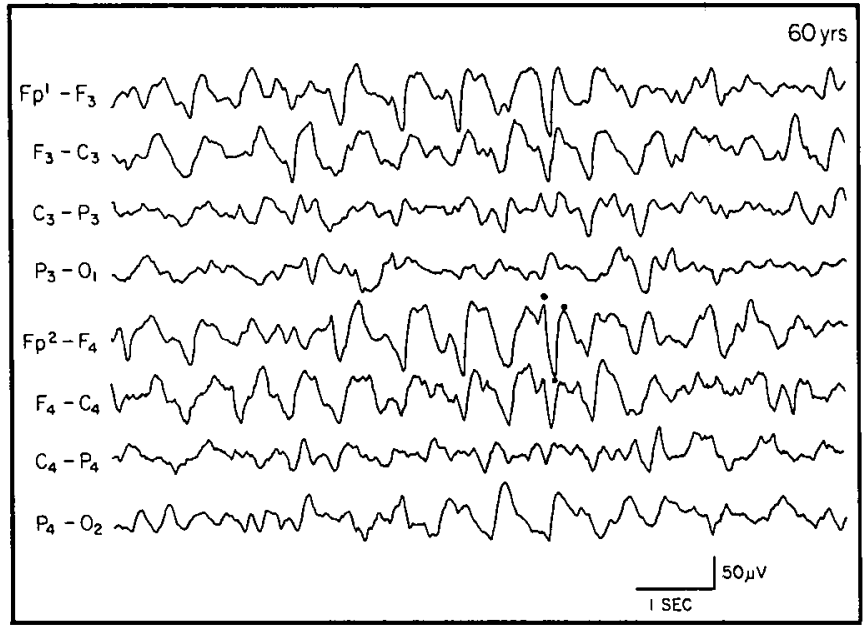

Figure I - A burst of triphasic waves, some of which have 3 well-defined peaks (dots). Posterior-anterior delay in dotted triphasic wave. Dots indicate peaks of Waves I, II and III sequentially as negative-positive-negative sequence. Note bisynchrony and maximum expression anteriorly. Some TWs in burst incompletely defined, possibly from intermingled diffuse delta. Hepatic encephalopathy.

\section{Clinical Data}

Hospital charts and EEG technologists' observations gave clinical diagnosis, conscious level at recording, and laboratory results. Level of consciousness at recording was divided into: Class I - awake but confused and/or demented, Class II obtunded or stuporous but able to obey simple commands when roused, and Class III - comatose with only response being withdrawal to pain. Brain stem reflexes were present in all patients.

Metabolic encephalopathy was defined as a diffuse disturbance of cerebral function consequent to failure of an organ or system outside the central nervous system.

Triphasic Waves with Sharp and Slow Wave Complexes (Slow Spike-Waves)

One hundred randomly selected EEGs (67 patients) containing sharp and slow wave complexes (SSWC) were searched for TWs. Such TWs were further analysed for relative amplitudes of individual components and anterior-posterior or posterioranterior delay.

\section{RESULTS}

\section{Etiology}

Twenty-six of the 63 patients (41\%) had metabolic encephalopathies of which recent hypoxia was the most common etiology (Table I). Senile dementia of the Alzheimer type was the most common clinical diagnosis among the 37 patients who did not have a metabolic encephalopathy.

\section{Prognosis}

Nine of the 24 patients with metabolic encephalopathies for whom data were available had died over a follow-up period averaging 2.5 years. Most of these 9 died within days or weeks of the recording containing triphasic waves. Eleven suffer chronic illness, usually hepatic. Only four were well. In contrast, only two of 35 non-metabolic patients for whom follow-up data were 
available had died. All but one of the 33 surviving patients have a chronic dementing illness. Follow-up period averaged 2.4 years for non-metabolic patients.

\section{Relative Amplitudes of Triphasic Wave Components}

Wave II was usually the largest (Table 2) followed in incidence by equally prominent waves I and II (Figure 2); equal prominence of components II and III appeared less often (Figure 3). Equal amplitude of all three waves rarely occurred. Wave 0 appeared in five EEGs but bursts with wave 0 formed less than $5 \%$ of the TWs in these recordings. Sporadically, wave I was sharply contoured and these TWs resembled SSWCs; although such TWs were seen in 14 EEGs, these occupied less than $5 \%$ of all triphasic bursts in any recording.

Metabolic and non-metabolic encephalopathies did not differ significantly with respect to relative amplitudes (Table 2).

\section{Distribution}

The area of distribution of TWs varied little throughout a tracing. In the metabolic encephalopathy group, TWs appeared principally anteriorly in 22 EEGs, posteriorly in 3 , and were diffuse in one. In the non-metabolic group TWs were maximum anteriorly in 24 , posteriorly in 4 and were diffuse in 12 EEGs.

\section{Delay}

Surprisingly, the number of patients with posterior-anterior delays or lags of the Wave II peak far exceeded the more classical anterior-posterior delay in the metabolic group (Table 3). Moreover, within the metabolic group, such lags were also

\begin{tabular}{cc}
\hline Table 1: Triphasic Waves: Associated Conditions \\
\hline \hline Metabolic: 26 patients (26 EEGs) & \\
Hypoxic encephalopathy & $: 6$ patients \\
Hepatic failure & $: 6$ \\
Renal failure & $: 2$ \\
Multiple metabolic dysfunction & $: 32$ patients \\
Non-Metabolic: 37 patients (40 EEGs) & $: 1$ \\
Dementia* & $: 1$ \\
Cerebral infarction & $: 2$ \\
Subdural hematoma & \\
Felty's syndrome with cerebral vasculitis & 1 \\
Suspected transient ischemic attacks & $:$ \\
\hline
\end{tabular}

*Clinical diagnosis without pathological verification.

Table 2: Relative Amplitudes of Triphasic Wave Components \begin{tabular}{ccc}
$\begin{array}{c}\text { Metabolic } \\
\text { Group }\end{array}$ & $\begin{array}{c}\text { Non-Metabolic } \\
\text { Group }\end{array}$ Total \\
\hline
\end{tabular}

Most frequent pattern

of largest component(s):

\begin{tabular}{lrrr} 
Wave II only & 16 & 27 & 43 \\
Waves I \& II & 8 & 11 & 19 \\
Waves II \& III & 1 & 2 & 3 \\
Variable combinations & 1 & 0 & 1 \\
cond most frequent pattern & & & \\
largest component(s): & & & \\
Waves I \& II & 9 & 22 & 31 \\
Wave II only & 6 & 13 & 19 \\
Waves II \& III & 7 & 3 & 10 \\
Variable combinations & 4 & 2 & 6 \\
\hline
\end{tabular}

Numbers $=$ EEGs

Waves I \& II, II \& III = components of approximately equal amplitudes associated with non-hepatic conditions. Delays appeared less commonly in the non-metabolic group $(p<.10)$, and had no preponderant direction.

\section{Quantity, Mode of Occurrence and Conscious Level}

In the metabolic group no patient was awake whereas in the non-metabolic group the majority of patients was awake and none was comatose. Conversely, all alert patients with TWs had non-metabolic encephalopathies and all comatose patients had metabolic conditions (Table 4).

TWs were more plentiful in the EEGs of the metabolic group than in those patients with non-metabolic encephalopathies (Table 4) if conscious level is not considered. Their quantity

STUPOROUS

Figure 2 - Triphasic waves whose Waves I, II have the highest amplitudes.

Post anoxic encephalopathy.

COMATOSE 45 yrs

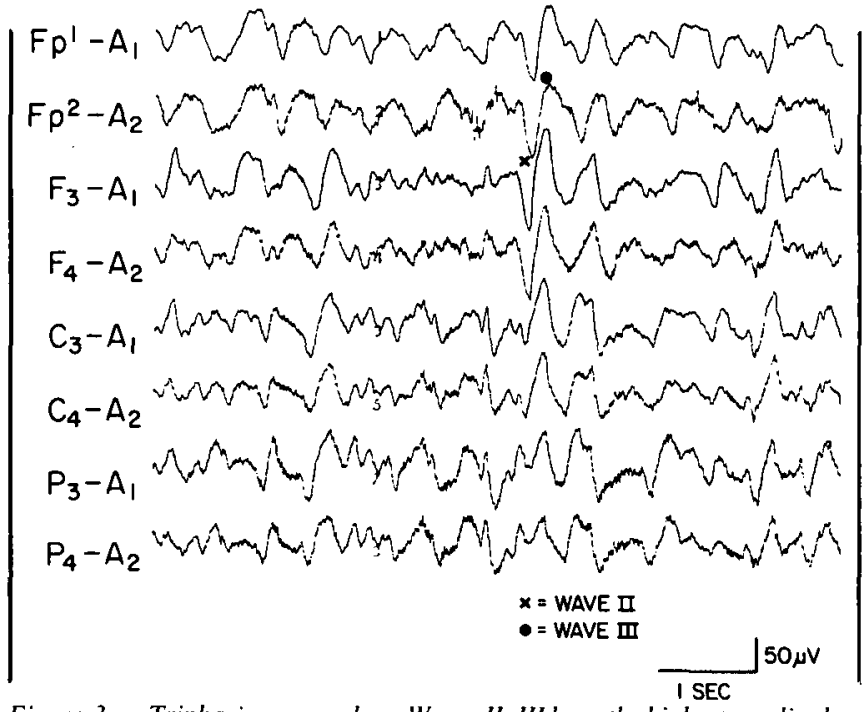

Figure 3 - Triphasic waves whose Waves II, III have the highest amplitudes. Hepatic encephalopathy.

\begin{tabular}{lcc}
\hline \multicolumn{2}{l}{ Table 3: Longitudinal Lag of Wave II Peak } & \\
\hline \hline & $\begin{array}{c}\text { Metabolic } \\
\text { Group }\end{array}$ & $\begin{array}{c}\text { Non-Metabolic } \\
\text { Group }\end{array}$ \\
\hline i) Anteroposterior only & $1(4)$ & $5(12.5)$ \\
ii) Posteroanterior only & $10(38)$ & $5(12.5)$ \\
iii) Both i) and ii) & $4(15)$ & $4(10)$ \\
iv) No lag & $\underline{11}(42)$ & $\underline{26}(65)$ \\
Total & 26 & 40 \\
\hline
\end{tabular}

Numbers = EEGs; ()$=$ percent 
was moderate or abundant in 15 of 26 metabolic patients (58\%) but were so in only 11 of 37 non-metabolic patients (30\%). As would be expected, mode of occurrence (bursts or runs) paralleled overall quantity.

However, both quantity and mode of occurrence of triphasic waves were strongly influenced by conscious level. No difference in quantity or mode of appearance of TWs existed between these groups when only stuporous or obtunded patients were considered. Therefore, differences in quantity and mode of occurrence between metabolic and non-metabolic groups reflect conscious level rather than etiology.

\section{Background}

Background activity was abnormal in all patients for both groups. Background was composed of delta and theta frequencies in the metabolic group with delta predominating. Mixed alpha and theta frequencies (6 patients) or theta and delta activity ( 31 patients) formed the background in the non-metabolic group, but delta predominated in only two of these recordings. However, the 2 groups could not be reliably distinguished by background.

\section{Triphasic Waves and Sharp and Slow Wave Complexes (Slow Spike-Waves)}

Of 100 randomly selected EEGs (67 patients) containing SSWC, 40 recordings ( 23 patients) showed at least 1 triphasic burst per tracing (Figure 4). However, in any 30 minute tracing these triphasic bursts were rare: in 34 EEGs less than 5 appeared; in 6 recordings, 6 to 10 occurred. The close resemblance of the rarely appearing TWS to SSWCs likely explains our initial failure to classify them separately.

The relative amplitudes of TW components differed from those of the previously discussed clinical entities. In 23 EEGs, Waves II and III were equally most prominent; in 14, all 3 waves were equal in size; in 2 recordings, Wave II alone was the most prominent; in only I EEG were waves I and II the most prominent. Wave III in most of these recordings was broad. TWs

\begin{tabular}{|c|c|c|c|c|}
\hline & Alert & $\begin{array}{l}\text { Obtunded/ } \\
\text { Stuporous }\end{array}$ & Comatose & Totals \\
\hline \multicolumn{5}{|l|}{ Quantity } \\
\hline $\begin{array}{l}\text { Metabolic Group } \\
\text { Minimal } \\
\text { Moderate } \\
\text { Abundant }\end{array}$ & $\begin{array}{l}0 \\
0 \\
0\end{array}$ & $\begin{array}{l}6 \\
4 \\
3\end{array}$ & $\begin{array}{l}5 \\
4 \\
4\end{array}$ & $\begin{array}{r}11 \\
8 \\
7\end{array}$ \\
\hline $\begin{array}{l}\text { Non-Metabolic } \\
\text { Minimal } \\
\text { Moderate } \\
\text { Abundant }\end{array}$ & $\begin{array}{r}23 \\
6 \\
2\end{array}$ & $\begin{array}{l}3 \\
3 \\
0\end{array}$ & $\begin{array}{l}0 \\
0 \\
0\end{array}$ & $\begin{array}{r}26 \\
9 \\
2\end{array}$ \\
\hline Mode of Occurre & & & & \\
\hline $\begin{array}{l}\text { Metabolic Group } \\
\text { Single bursts } \\
\text { Short runs } \\
\text { Long runs }\end{array}$ & $\begin{array}{l}0 \\
0 \\
0\end{array}$ & $\begin{array}{l}4 \\
5 \\
4\end{array}$ & $\begin{array}{l}5 \\
5 \\
3\end{array}$ & $\begin{array}{r}9 \\
10 \\
7\end{array}$ \\
\hline $\begin{array}{l}\text { Non-Metabolic } \\
\text { Single bursts } \\
\text { Short runs } \\
\text { Long runs }\end{array}$ & $\begin{array}{r}23 \\
8 \\
0\end{array}$ & $\begin{array}{l}1 \\
4 \\
1\end{array}$ & $\begin{array}{l}0 \\
0 \\
0\end{array}$ & $\begin{array}{r}24 \\
12 \\
1\end{array}$ \\
\hline
\end{tabular}

Numbers $=$ patients appeared anteriorly in 23 recordings, diffusely in 13, and posteriorly in 4. TWs occurred only among SSWCs in 30 EEGs; in the remaining 10, they occurred both among and separate from SSWCs. Anterior-posterior delay of TWs appeared in only 2 EEGs and posterior-anterior delay in 2 . The delay in each case was less than 50 milliseconds.

All patients in this group were alert at the time of recording. All had chronic generalised seizure disorders and were mentally subnormal. None had a metabolic encephalopathy and none had documented dementia.

\section{Discussion}

The bilaterally synchronous EEG pattern examined here was first called "triphasic waves"' by Bickford and Butt (1955) ${ }^{2}$ who described them as follows: "The main deflection is downward, indicating a surface positive change. The main deflection is usually preceded and followed by low-amplitude negative deflections giving the whole complex a triphasic contour'. Markand (1983) ${ }^{7}$ stated that the initial negative component is briefer than the positive deflection while the subsequent negative wave is the longest. However, relative durations of components are not prerequisite in identifying the wave form.

In our study of TW morphology, amplitude of Wave II most commonly exceeded those of Waves I and III while equally tall Waves I and II appeared next most frequently (Table 2). The negative Waves I and III never exceeded Wave II in amplitude. Note that the relative amplitudes of the 3 components failed to distinguish metabolic from non-metabolic encephalopathies (Table 2).

Bickford and Butt (1955) and Reiher (1970) ${ }^{2.4}$ indicated the bisynchronous character of these bursts, an essential criterion. While many writers ${ }^{2-5}$ found that most bursts were maximally expressed frontally, Bickford and Butt found that a minority of TWs arose in the "Sylvian regions" and in the occipital area." Our findings are similar: most TWs appeared maximally in the frontal regions while a minority was situated posteriorly or was diffusely distributed.

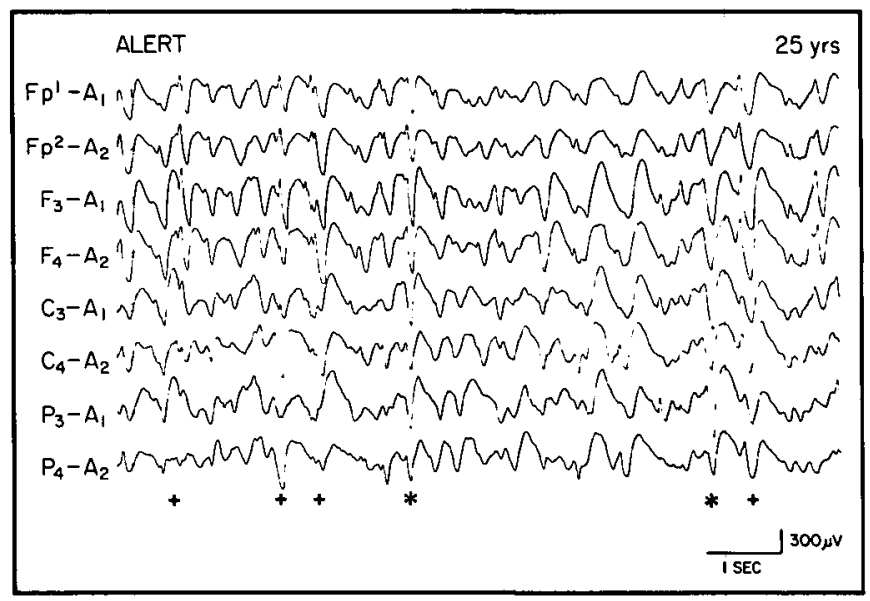

Figure 4 - Triphasic waves and sharp and slow wave complexes (slow spike waves). All illustrated paroxysmal waves share features of each entity, but * more resemble triphasic waves while + contain sharper Waves I giving a sharp and slow wave complex allure. Patient with seizure disorder and Lennox-Gastaut Syndrome. 
A variety of conditions within the broad categories of metabolic and non-metabolic encephalopathies are represented in our TW patient group (Table 1). As with all other studies, the relative proportion of such diseases was likely influenced by our laboratory referral pattern. Although Foley et al (1950) ${ }^{1}$ initially claimed that TWs were specific for hepatic coma, Adams and Foley $(1953)^{8}$ expanded the association to include other coma-producing metabolic conditions. Bickford and Butt (1955) focused on hepatic coma in studying TWs, but they also recognised that similar waves could appear in association with other conditions including ether anesthesia and convulsive disorders. ${ }^{2}$ Although their review of 345 patients with coma of non-hepatic origin failed to reveal any case with TWs, anoxic encephalopathy and uremia were represented by only one case each. Subsequent authors have found TWs with: several types of metabolic encephalopathies, post anoxia, degenerative conditions, head trauma, congestive heart failure, basilar artery insufficiency, and other conditions. ${ }^{9.4 .5 .7}$ However, the incidence of TWs is highest among patients with hepatic encephalopathy. ${ }^{5}$

Reiher (1970) extended the correlation with hepatic coma further. ${ }^{4}$ From a study of 67 patients with TWs, he concluded that "typical" TWs (i.e. those occurring in groups and long runs, are bilateral, symmetrical, synchronous, maximal anteriorly with an anterior-posterior lag and superimposed on a slow background) are pathognomonic for hepatic coma. In contrast, he found "atypical" TWs, i.e. those without all the features of "typical" TWs, in a variety of conditions, including hepatic encephalopathy. Unfortunately, in clinical practise "typical" TWs are much less common than are the atypical forms. For example, an anterior-posterior lag appeared in only 3 of 42 patients with TWs in Simsarian and Harner's study. ${ }^{5} 14$ of our 63 cases showed a longitudinal delay but each failed to show one or more of the other obligate features of typical TWs proposed by Reiher. ${ }^{4}$ Reiher's abstract does not indicate the number of patients with the "typical" forms upon which his conclusion is based nor the number and variety of metabolic encephalopathies studied. ${ }^{4}$ In the Simsarian and Harner (1972) study, hepatic encephalopathy appeared in only two of the three patients with an anterior-posterior time lag of their TWs. ${ }^{5}$ Typical TWs were found in both hepatic and renal encephalopathy by Karnaze and Bickford (1984). ${ }^{6}$

In our material a posterior-to-anterior lag of Wave II occurred more commonly than an anterior-to-posterior lag. Such lags occurred with hepatic and non-hepatic metabolic encephalopathies as well as (less commonly) non-metabolic diffuse conditions. Therefore, our data indicate that a longitudinal lag of Wave II carries no etiological implication.

The clinical significance of triphasic waves depended more on conscious level at time of recording than on any of their morphological aspects or on the nature of EEG background. Awake but confused patients all had non-metabolic encephalopathies, particularly senile dementia of the Alzheimer type whereas all unrousable patients had metabolic encephalopathies.
The prognostic significance of triphasic waves has not changed over the years. The longest survival time of Bickford and Butt's 13 patients with triphasic waves was 6 weeks. ${ }^{2}$ Twenty-nine years later Karnaze and Bickford (1984) reported that the majority of patients in most etiological categories died. ${ }^{6}$ Although less than half of our patients with TWs died, only 5 of 59 followed patients were well over 2 years later.

Foley et al (1950) and Bickford and Butt (1955) noted the occasional resemblance of TWs to "certain atypical bilaterally synchronous discharges" in EEGs of epileptic children. ${ }^{1,2}$, SSWCs (slow spike-waves) have many features in common with TWs: three components (spike, trough, and slow wave) which appear in bilaterally synchronous frontally predominant groups or runs on a slow background. The relative durations of the three components of some TWs are those of SSWC, i.e. first component shortest, third component longest (Markand, 1983). ${ }^{7}$ Therefore, it is not surprising that our re-examination of 100 EEGs containing SSWC found sporadic TWs in 40.

The relative amplitudes of the three components of TWs occurring in EEGs with SSWC differ from most TWs seen with other conditions. Waves II and III were the largest or all three waves were equally large in 37 of 40 EEGs with SSWC.

Why TWs should appear in association with SSWC is unclear. They may simply be an extreme variation of SSWC as transitional forms do exist. They also could represent diffuse cerebral dysfunction produced by the abundant epileptiform paroxysms.

\section{ACKNOWLEDGEMENTS}

We wish to thank Mrs. Maria Raffa for her secretarial assistance.

\section{REFERENCES}

1. Foley JM, Watson CW, Adams RD. Significance of the electroencephalographic changes in hepatic coma. Trans Amer Neurol Ass $1950 ; 75 ; 161-164$

2. Bickford RG, Butt HR. Hepatic coma: the electroencephalographic pattern. J Clin Invest 1955; 34: 790-799.

3. Silverman D. Some observations of the EEG in hepatic coma. Electroenceph Clin Neurophysiol 1962; 14: 53-59.

4. Reiher J. The electroencephalogram in the investigation of metabolic comas. Electroenceph Clin Neurophysiol 1970; 28: 104P.

5. Simsarian JP, Harner RN. Diagnosis of metabolic encephalopathy: significance of triphasic waves in the electroencephalogram. Neurology 1972; 22: 456.

6. Karnaze DS, Bickford RG. Triphasic waves: a reassessment of their significance. Electroenceph Clin Neurophysiol 1984; 57: 193-198.

7. Markand ON. Abnormalities associated with diffuse encephalopathies. State of the Science in EEG. Presented at the American Electroencephalographic Society annual course New Orleans, Louisiana, October 1983.

8. Adams RD, Foley JM. The neurological disorder associated with liver disease. Assoc Res Nerv and Ment Dis Proc 1953; 32: 198-237.

9. Fischgold H, Mathis P. Obnubilations, comas et stupeurs. Electroenceph Clin Neurophysiol 1959; Suppl 11: 50. 